\title{
フーリエ解析機による波浪・動摇の解析について
}

\section{On the Analysis of the Ship's Oscillations induced by Ocean Waves using Fourier Analyser}

\section{八反田吉常・川島利兵衛・稻葉 恭人 (北海道大学水産学部)}

\begin{abstract}
In their studies of ship's oscillations in a seaway, in order to analyse a large amount of data concernig ship's oscillations automatically in a short time, the authors used a Fourier Analyser, a kind of electronic analog computer, which was designed so work as in M. J. Tucker and T. B. Whiteley's way.

A view of the whole apparatus and diagram illustrating the principle of the Fourier Analyser are shown in Photo. 1 and Fig. 2 respectively.

By this apparatus, the spectra of ship's oscillations and wave heights were calculated on some examples which were discussed in the former paper by one of the authors.

Results of the calculation are shown in Figs. 8, 9, 10 and 11.

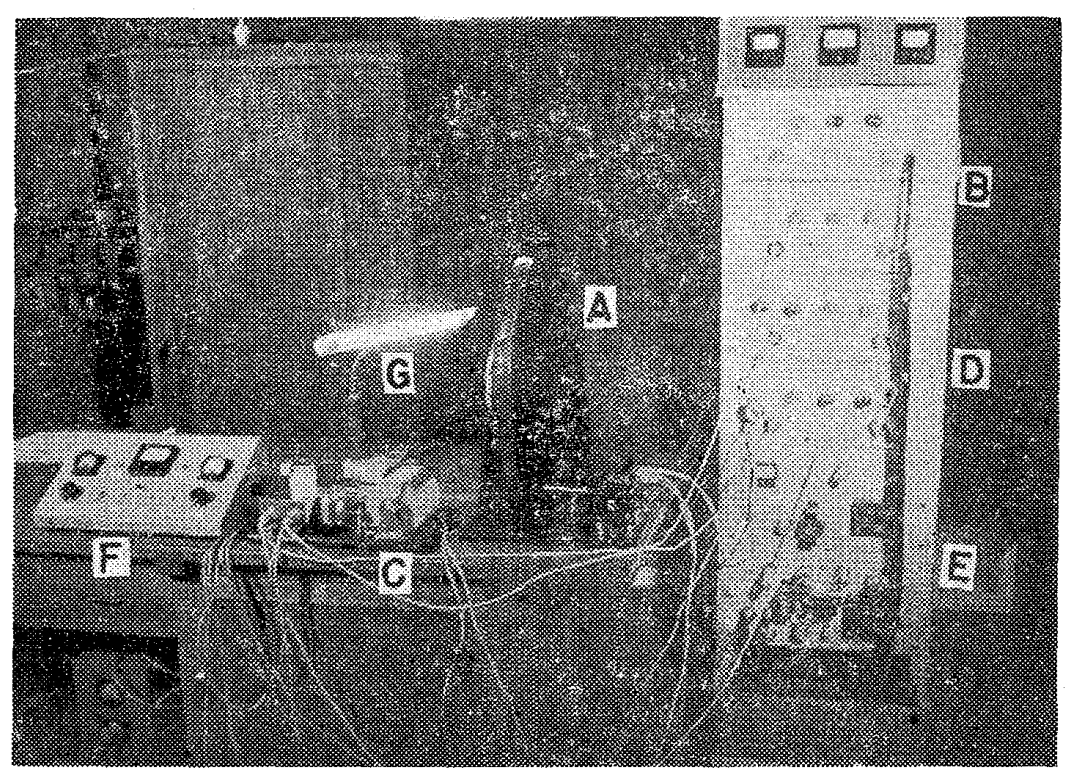

Phots. 1

Photo. 1 A view of Fourier Analyser

A : Rotating Wheel B : Amplifier, Filter and Rectifier

C : Recorder D : Servo Amplifier $E$ : Power Supply

F : Control Panel G : Flush light for Storovo image

\section{1. 緒 言}

海上に於ける船の運動を解 析することによつて、実際の 操船の役に立つ様な定量的な 結果を得るには、種々な条件 の下で得られる沢山のデータ の集積と処理を必要とする。 大洋波の中を航行する船の 動摇について、そのデータを 分析処理するために、自働的 方法としてフーリエ解析機を 使用した。

著者等は、M. J. Tucker. ${ }^{1)}$

T. B. Whiteley ${ }^{2}$ 等と同じ棁 な型式のフーリエ解析機を用 いて、海上で計測記録された
\end{abstract}


波高と船の横摇れ角について演算し、且つ、同一記録の見掛けの波高周期及び横摇れ角、周期か ら計算したエネルギースペクトルとの比較をした。

\section{2. フーリエ解析機}

スペクトラムについて・

周期函数のフーリエ級数を複素表示すると、

$$
\begin{aligned}
f(t) & =\sum_{-\infty}^{+\infty} A_{n} \exp \left(z n \omega_{0} t\right) \quad \ldots \ldots . . \\
\text { 但し、 } A_{n} & =\frac{1}{T_{0}} \int_{-\frac{T_{o}}{2}}^{\frac{T_{o}}{2}} f(t) \exp \left(-j n \omega_{0} t\right) d t
\end{aligned}
$$

係数 $A_{n}$ は $n \omega_{\mathrm{J}}(\omega=2 \pi f=2 \pi / T)$ の調和成分の振门と位相を示す複素数で、波形の長さ $T_{0}$ の周期を無限に増加すると、 $\lim _{T \rightarrow \infty} \frac{1}{T_{0}}=d f=\frac{d \omega}{2 \pi}$ となり (1) は積分の形になる。

今、函数 $g(t) 、 G(\omega)$ そついて

$$
g(t)=\frac{1}{2 \pi} \int_{-\infty}^{\infty} G(\omega) \exp (j \omega t) d \omega
$$

$G(\omega)=\int_{-\infty}^{\infty} g(t) \exp (-j \omega t) d t$

について、(4)式は、周波数 $\omega$ に対して $G(\omega)$ の振门をとると、 $g(t)$ に対する周波数範囲に於け るエネルギーの分布を示す带域スペクトルとして表わされる。 $t_{0}<t<t_{0}+T$ の範囲で、今 $t_{0}=0$ とすると(4)は、

$$
G(\omega)=\int_{-\frac{T_{0}}{2}}^{\frac{T_{0}}{2}} g(t) \exp (-j \omega t) d t
$$

從つて(2)(5)から

$$
f(t)=g(t)
$$

故に $A_{n}=G\left(n \omega_{0}\right) / T_{0}$

$g(t)$ からなる周期函数 $f(t)$ を㓮期 $T_{0}$ で繰返すと、周波数 $n \omega_{0}$ に対して得られる振门 $A_{n}$ は、スペクトラム $G(\omega)$.上の点である。

フーリエ解析機について。

本機の演算、記録部の全景を Photo 1 亿示す。機構は、(1)解析する波形を $35 \mathrm{~mm}$ フイルムに 毛黒に写す、(2)前項の波形を電気的信号に変換する、(3)電気的信号について演算する。(4)演算結 果を記録する、の4 部分からなる。

作動の概略は次の通りである。

i ）解析する波形をFig. 1 に示す様にグラフ用紙に画き切り抜いて $35 \mathrm{~mm}$ フイルムの上にお 


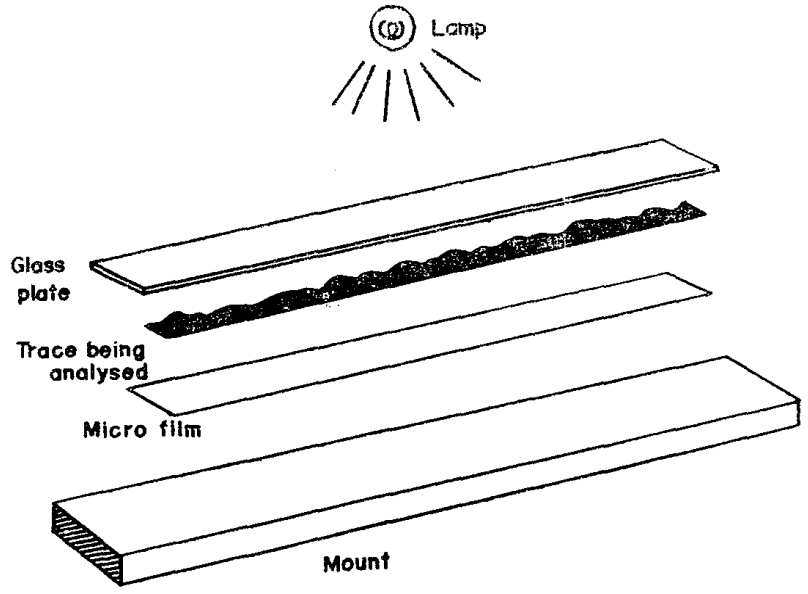

Fig. 1

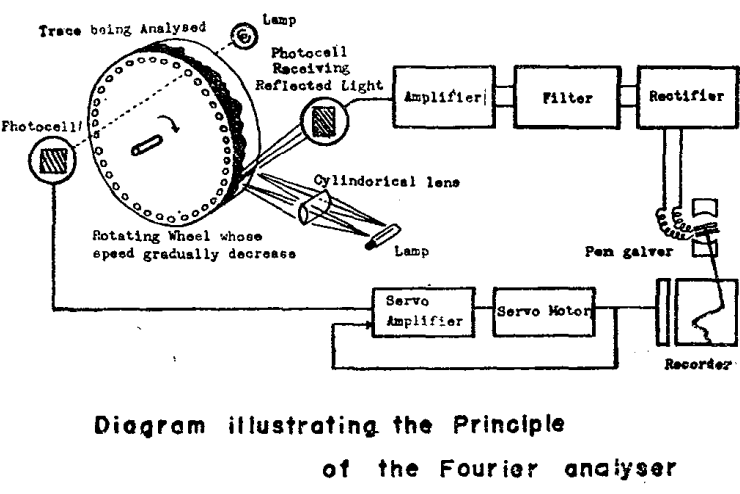

Fig. 2

き、露光して白黒の波形のフイルムを作るとのフイルムを繰返す（ループにする）ととにより 周期的とすれば、このフーリ工級数の成分は原の波形の連続周波数分布に関係する。

ii)白黒の波形フイルムを Fig. 2 の回転ドラムの周囲に捲くとループが出来る。フイルムの長 さは $159.6 \mathrm{~cm}$ 、之に線光線を当てその反射光を光電管に受けると波形は電気的な波形となり、增 门器を通つてフイルター回路に入る。回転ドラムの回転速度の変化はフイルターの值を変るとと になり、本機のフイルターの值は $312 \mathrm{c} / \mathrm{s}$ になりドラムの回転を 360 R.P.M から 20R.P.M に 減衰する間に、フイルム上の波形について長さ $30.7 \mathrm{~mm}$ 加ら $1.7 \mathrm{~mm}$ の成分波に解析出来る。之 は、1秒 $2 \mathrm{~mm}$ としてフイルムを作ると 1 秒から15秒の波に分析出来る。

iii）一方、他の光学系により回転ドラムの減衰速度の変化量に比例して記録ドラムを回転させ て、周波数スペクトラムを約 20 分間でペン書オツシロによつて記録する。

回転ドラムの減衰曲線及びフイルター特性を Fig. 3 及び 4 亿示す。

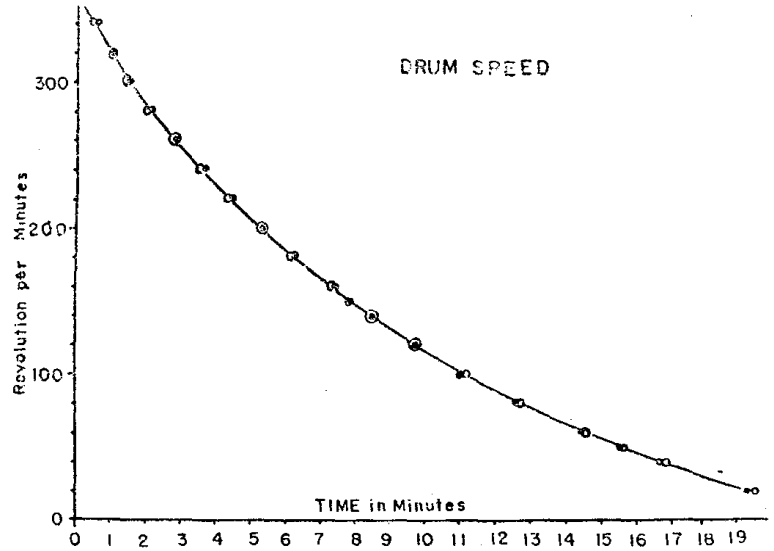

Fig. 3

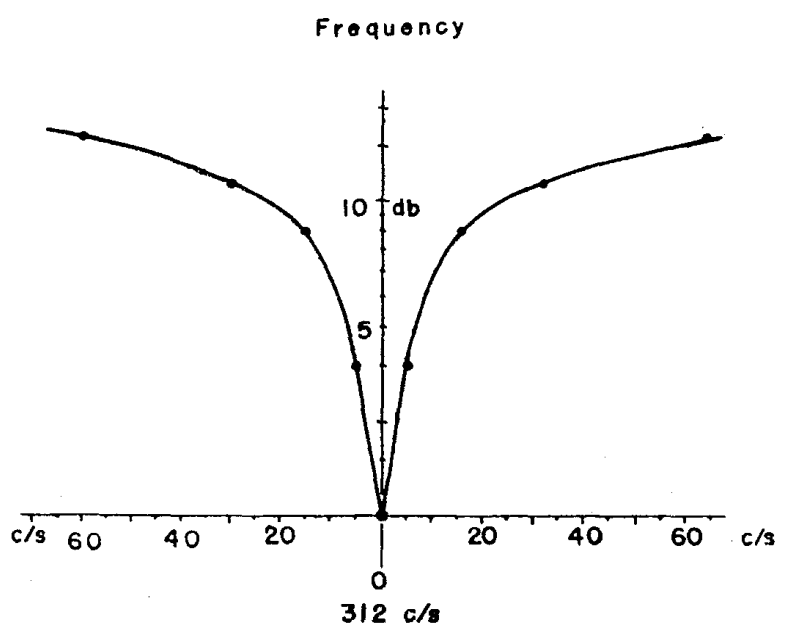

Fig. 4

\section{3. 波高及び横搖れ角の解析}

前文 ${ }^{3)}$ 亿於いて、実験解析された巡視船「りしり」の波浪中の横摇れの記録について、本機によ り演算した。

解析に用いた波高及び横弾れ角の記録の一部在 Figs.5、6及び7亿示す。 
RISHeP ROLLING EXP. IN TSUOARU

DRIFTINO

WAVE HIOHT

Fig. 5

\section{$\hat{x}$}

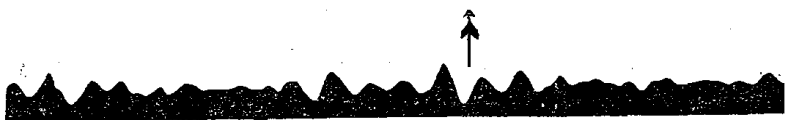

Fig. 7

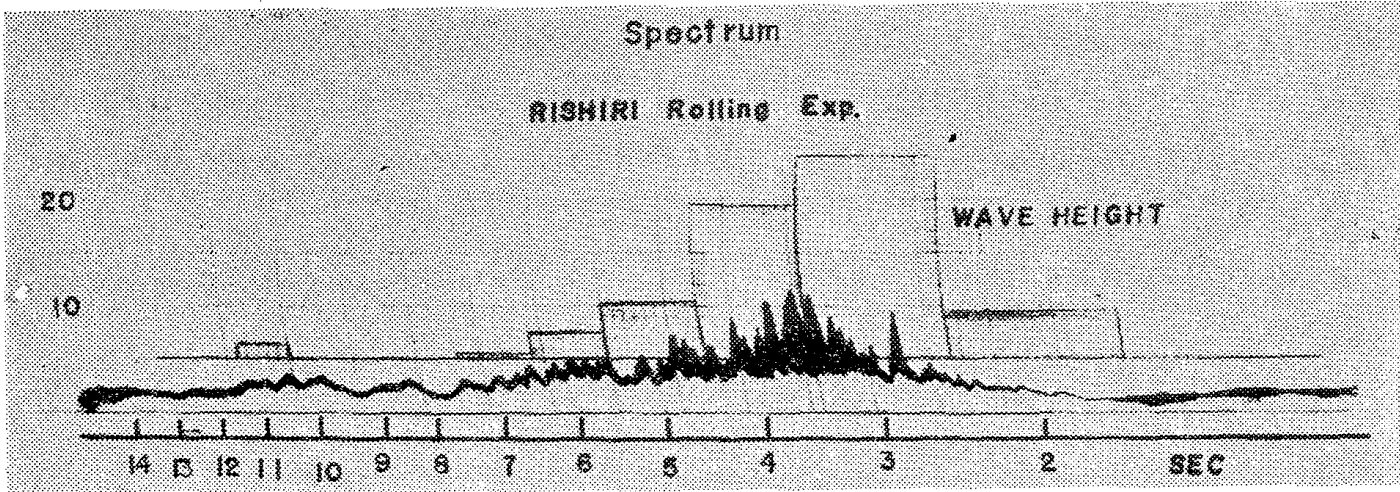

Fig. 8

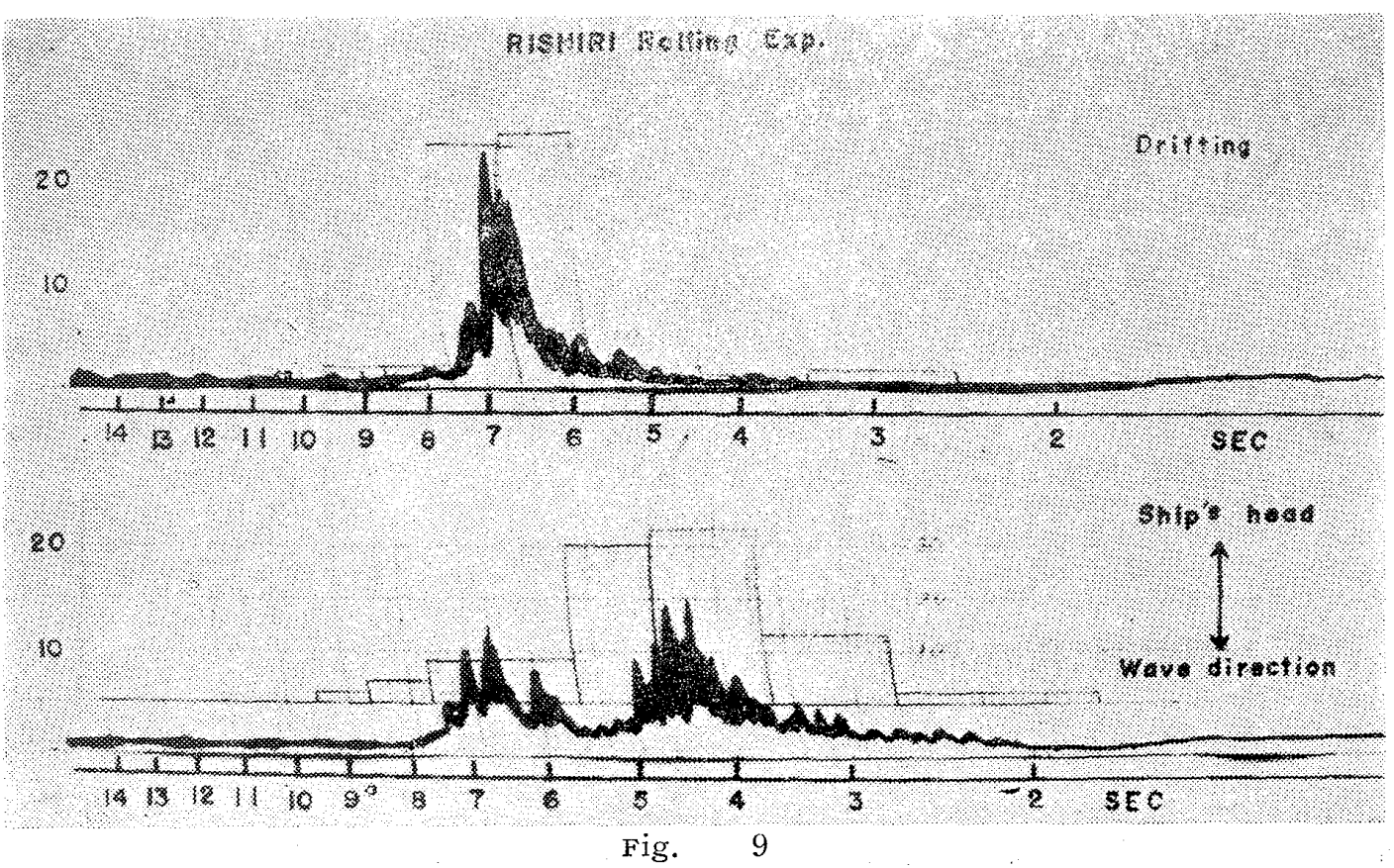




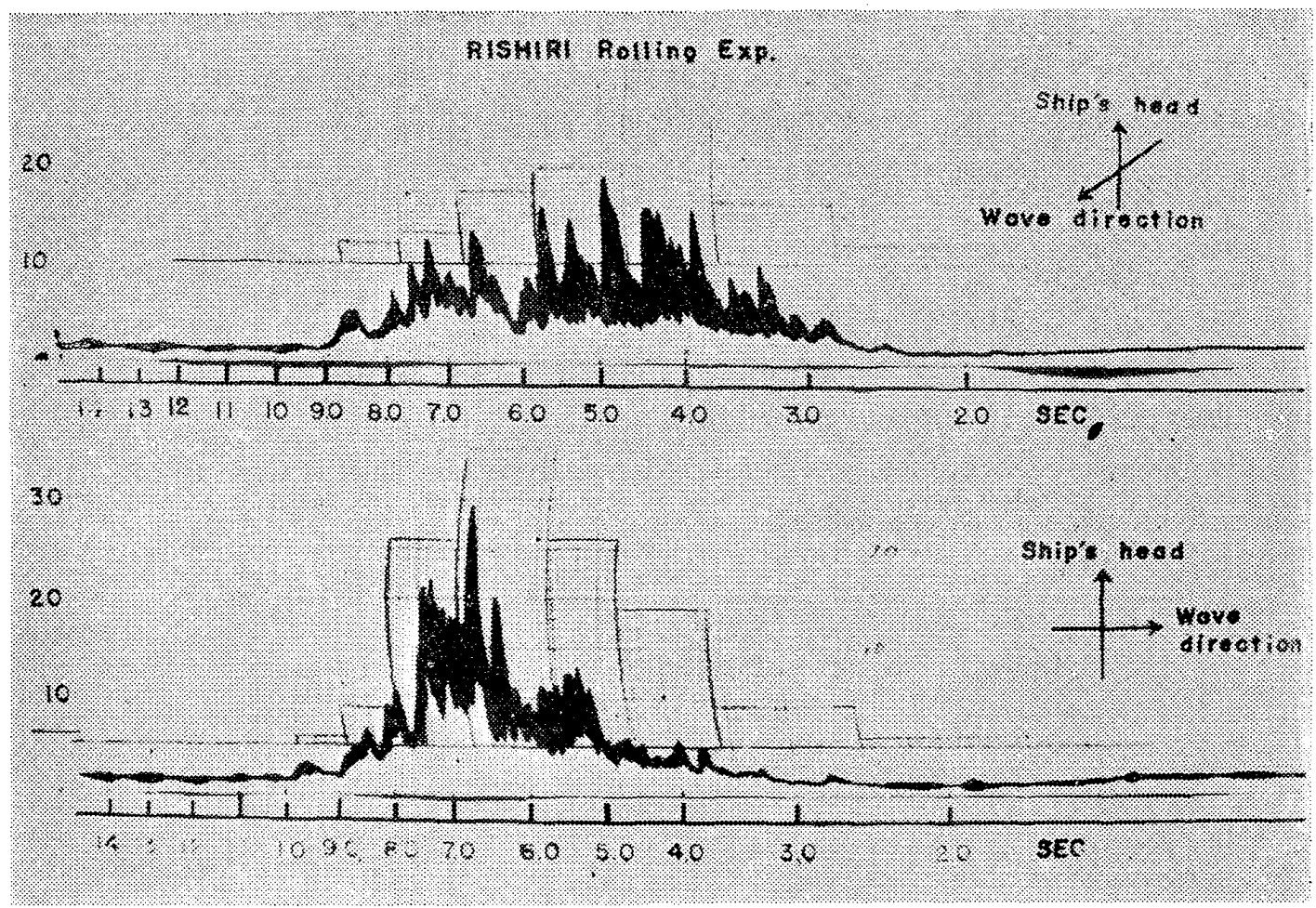

Fig. $\quad 10$

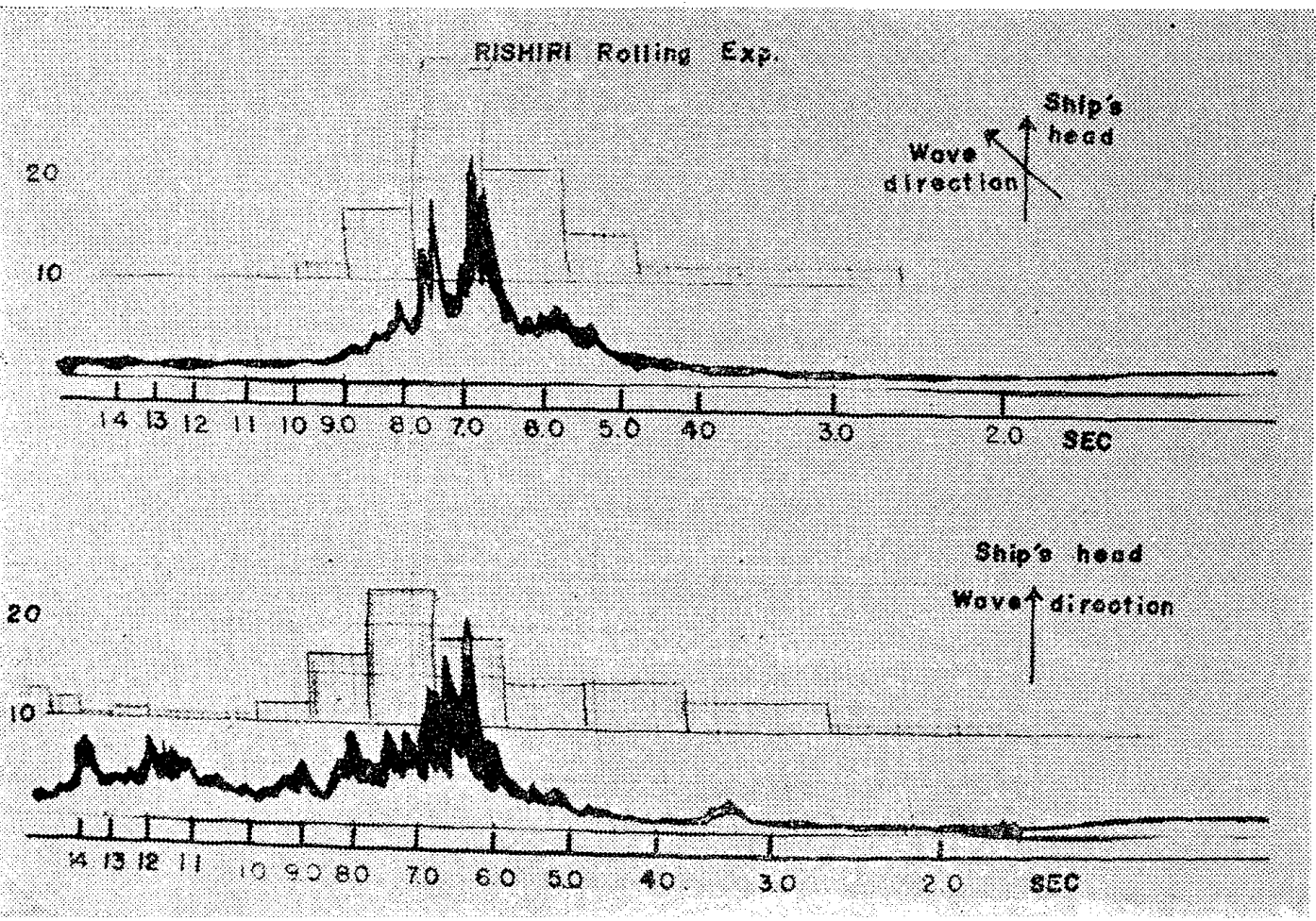

Fig. $\quad 11$

\section{4. 結言}

本㙨による演算結果とエネルギースペクトルとを比較すると大体同程度の結果を得られたもの と考光る。

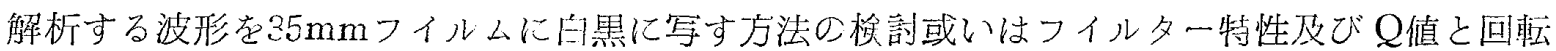


ドラムの減衰等を更に改良する予定である。

本機の詳細については別の機会に報告する。最後に、フーリエ解析㙨の製作については、東大 地震研究所高橋教授並びに相田氏の御指導、御助力に深謝する。

尚，本研究は、文部省科学研究費交付金により実施した。

参 考 交 献

1 ) Barber, N. F., Ursell F., Darbyshire J, and Tucker M. J. (1946)

A frequency analyser used in the Study of Ocean Waves. Nature No. 158 pp 329-332.

2) Whiteley T. B. and Alldredge L. R. (1951)

A photomechanical wave analyser for Fourier analysis of transient wave form.

Jour. Sci. Jnst. Vol. 29 pp 358.362

3 ) 川島利兵衛 (1960)

津軽海陕に於ける波による船の動摇の実験について

日本航海学会誌 No. 22 pp131-142 